\title{
Effect of Taping Technique Applied to Adults with Knee Instability on Landing Error Scoring System, Lower Extremity Joint Angle
}

\author{
Jin-Kyu Son ${ }^{(\oplus)}$, Sam-Ho Parka ${ }^{\circledR}$, Myung-Mo Lee ${ }^{b}$ \\ aDepartment of Physical Therapy, Graduate school, Daejeon University, Republic of Korea \\ ${ }^{b}$ Department of Physical Therapy, Daejeon University, Republic of Korea
}

Objective: The purpose of this study was to investigate effects of taping technique applied to knee instability.

Design: Cross sectional study.

Methods: Twenty-six participants with knee instabilityparticipated in this study. They were randomly assigned to the Kinesio taping (KT) group $(n=13)$ and the dynamic taping (DT) group $(n=13)$. Both groups applied knee stabilization taping techniques. In order to compare the effects of each taping technique, the change in the landing error scoring system (LESS) and lower extremity joint angle wasrecorded before and after the intervention.

Results: Both groups significantly decreased in the change before and after the LESS $(\mathrm{p}<0.05)$. At the joint angle of the lower extremities, KT group significantly reduced the valgus angle at the max knee flexion $(p<0.05)$. In DT group knee joint flexion and hip joint flexion angles were significantly increased at foot contact $(p<0.05)$. In max knee flexion, the knee joint flexion angle was significantly increased $(p<0.05)$. In foot contact, max knee flexion, the knee joint valgus angle was significantly increased $(\mathrm{p}<0.05)$. DT group showed more significant changes in knee joint flexion angle at foot contact and hip joint flexion angle at max knee flexion.

Conclusions: Dynamic taping is a clinically applicable intervention method for lowering the risk of non-contact injury in participants with knee instability and for knee stability during rehabilitation exercises.

Key Words: Anterior cruciate ligament injuries, Athletic tape, Range of motion

\section{서론}

21세기 현대인은 건강에 대한 관심도가 높아짐에 따라 일상생활에 다양한 스포츠 활동을 수행하고 있다. 스포츠 활동의 수요가 증가함에 따라 스포츠 손상도 증가하고 있 으며, 그중 스포츠 손상 중 무릎관절 손상은 약 14 16\% 로 발목 관절 손상 다음으로 많은 빈도를 차지하고 있대[1]. 무릎관절 손상 중에 앞십자인대(Anterior Cruciate Ligament, $\mathrm{ACL}$ ) 손상은 가장 높은 손상빈도를 나타내는 곳으로써 손상원인을 분석한 결과비접촉성 손상 $72 \%$, 접촉성 손상 은 $28 \%$ 로 비접촉성 손상이 접촉 손상보다 월등히 높게 나타났다[2,3]. ACL 비접촉성 손상 원인으로는 방향 전
환 전의 급격한 감속, 방향 조절 실패, 점프 후 잘못된 착 지 등이 있으며, 특히 방향 전환과 감속, 점프 후 착지 등 으로 인한 스포츠 활동에서 $\mathrm{ACL}$ 손상이 가장 빈번하다 $[4,5]$.

스포츠 손상에 대한 관리의 중요성이 새롭게 인식되면 서 운동 손상의 예방의 필요성이 강조되고 있으며, 선행 연구에 따라 $\mathrm{ACL}$ 손상 예방을 위해 손상위험요인 평가 와 손상 위험성을 줄이는 중재를 제공하는 것은 매우 중 요하다[6]. 스포츠 현장에서는 ACL 손상위험요인을 알아 보기 위한 장비로 3 차원 동작 분석 시스템이 표준(gold standard)으로 받아들여지고 있다. 그러나 스포츠 현장에 서 모든 선수들에게 이를 적용하기에 시간 및 경비가 많

Received: Nov 8, 2021 Revised: Nov 28, 2021 Accepted: Dec 6, 2021

Corresponding author: Myung-Mo Lee (ORCID https://orcid.org/0000-0002-2192-170)

College of Health and Medical Science, Daejeon University.

Applied Science Building, 62, Daehak-ro, Dong-gu, Daejeon, 34520, Republic of Korea

Tel: +82-42-280-2294 Fax: +82-42-280-2295 E-mail: mmlee@dju.kr

This is an Open-Access article distributed under the terms of the Creative Commons Attribution Non-Commercial License (http://creativecommons.org/licenses/ by-nc/4.0) which permits unrestricted non-commercial use, distribution, and reproduction in any medium, provided the original work is properly cited.

Copyright $\odot 2021$ Korean Academy of Physical Therapy Rehabilitation Science 
이 소요되고 분석절차가 매우 복잡하여 착지오류점수시스 템(landing error scoring system, LESS)이 그 대안으로 활용되고 있다[7]. $\mathrm{LESS}\left(\mathrm{ICC}_{2, \mathrm{k}}=0.84, \mathrm{ICC}_{2,1}=0.91\right)$ 는 착지수직점프 검사와 관련된 착지 동작의 영상 분석을 통 해 이마면 영상에서 8 가지 항목을 평가하고 시상면에서 8 가지 항목을 평가, 마지막으로 이마면 그리고 시상면을 종합적으로 평가하여 비접촉성 ACL 손상의 위험성을 식별 하는 것으로 신뢰할 수 있는 임상적인 평가 도구이다[7].

스포츠 활동시 무릎관절의 손상예방을 위하여 무릎강 화운동, 보호대, 테이핑과 같은 중재 방법을 이용하고 있 다. 이 중 테이핑은 관절의 지지, 보호 역할로 기능적인 움직임을 수행할 수 있도록 도와주며 이러한 외적지지는 인대 보강 및 움직임의 제한을 통한 관절의 안정성을 기 대할 수 있다 $[8,9]$. 대표적인 테이핑 중 키네시오 테이핑 (Kinsio Taping, KT)은 치료용 탄성 테이프로서 통증을 줄이고 자가수용, 근육활동 및 관절가동범위를 증가시킴 으로써 스포츠 손상 예방 및 치료에 효과를 보여주었다 [10,11]. 또한 $\mathrm{KT}$ 는 $140 \sim 180 \%$ 탄성력을 가지고 있고 근육을 늘린 상태로 부착하여 피부를 들어올려 발생한 공 간을 통해 순환을 향상시키고, 통증에 민감한 구조에 대 한 압력을 줄여주는 신경생리학적 효과를 위한 테이핑이 라 하였다[12].

최근 호주 물리치료 Ryan Kendrick에 의해 개발된 탄 력 테이핑의 한 종류인 다이나믹 테이핑(Dynamic taping, DT) 또한 스포츠 손상 예방에 효과가 있다고 소개되고 있다[13]. DT는 $200 \%$ 이상의 탄성력과 더불어 수직방향 과 횡방향으로 늘어나는 저항성(resistance)과 복원력(recoil) 을 가지고 있다[14]. 이에 대하여 1차적으로 감속 작용 및 부하 흡수, 움직임을 보조하는 역할을 하고, 2차적으로 신 경생리학적인 효과를 제공하는 테이프로 소개되고 있다 [15].

선행 연구를 통해 다양한 테이핑 종류와 기법을 무릎 관절에 적용하여 가해지는 부하 및 통증 감소를 위한 연 구가 진행되어 오고 있다[12,14-16]. 특히, 최근 소개된 $\mathrm{DT}$ 와 $\mathrm{KT}$ 을 비교하여 효과를 비교한 연구들이 소개되고 있다[17]. 하지만 무릎 불안정성이 있는 성인 대상으로 테 이핑 종류에 따른 효과 비교 연구는 부족하며, 대부분의 탄력 테이핑과 비탄력 테이핑의 비교 연구로 범위가 제한 적이다.

이에 본 연구에서는 무릎 불안정성을 가진 대상자를 대 상으로 키네시오 테이핑과 다이나믹 테이핑을 적용하여 $\mathrm{LESS}$ 와 착지 시 하지 관절 각도의 변화를 비교하여 두 테이핑에 대한 효과를 알아보고 $\mathrm{ACL}$ 손상을 예방할 수 있는 정보를 제공하고자 한다.

\section{연구 방법}

\section{연구 대상}

본 연구는 $\mathrm{D}$ 시에 $\mathrm{D}$ 대학교 재학중인 20대 성인을 대상 으로 진행하였다. 대상자의 선정기준은 $50 \mathrm{~cm}$ 높이에서 지면으로의 점프 및 착지 동작 수행이 가능한 자, 착지오 류점수시스템(LESS) 평가 결과 6점(poor) 이상인 자, 테 이핑 부착에 대한 거부감이 없는 자로 선정하였다. 대상 자의 제외기준은 하지관절의 불안정성으로 인해 점프 및 착지 동작의 어려움을 호소하는 자, 최근 3 개월 이내에 하지의 염좌, 골절과 같은 급성 손상으로 인해 1 일 이상 신체 활동 중단을 경험한 자, 6 개월 이내에 하지의 뼈, 관 절, 신경에 대한 수술의 경험이 있는 자, 착지에 대한 시 각적 문제와 전정기능의 문제로 인해 평가 수행이 어려운 자로 기준으로 하였다. 본 연구는 기관생명윤리위원회의 승인을 받았으며(승인번호:1040647-202106-HR-001-02), 모집된 대상자에게 연구 동의를 얻은 후 진행하였다.

\section{연구 절차}

본 연구는 Cross sectional study로 대상자 수 산출을 위해 G-power를 이용하였다. Kwon[17] 등의 연구에서 메인효과의 결과를 참고로 효과크기(d)를 1.15 로 산출하 여 대입하였고, 유의수준 $(\alpha)$ 은 0.05 , 검정력 $(1-\beta)$ 은 0.8 설정 한 결과 그룹 당 13 명 총 26 명이 필요하였으며, 탈 락율 $20 \%$ 를 고려하여 총 32 명의 대상자를 모집하였다. 모집된 대상자 중 연구에 적합한 대상자를 선별하기 위해 사전 질문과 무릎불안정성 검사 LESS 평가를 진행하였 다. 선별검사 결과 LESS 5점 미만을 받은 대상자 $(n=4)$, 3 개월 이내의 급성 발목 손상 $(n=1), 6$ 개월 이내의 무릎 수술을 받은 대상자 $(\mathrm{n}=1)$ 가 탈락하여 최종 26 명의 대상 자가 실험에 참여하였다. 두 종류의 테이핑을 적용한 $\mathrm{KT}$ 그룹 및 $\mathrm{DT}$ 그룹이 점프 착지 후 즉각적으로 점프 동작에 서 LESS 점수 그리고 하지 관절 각도를 비교하기 위해 26 명의 대상자를 무작위 프로그램을 이용하여 $\mathrm{KT}$ 그룹 $(\mathrm{n}=13)$ 과 $\mathrm{DT}$ 그룹 $(\mathrm{n}=13)$ 으로 배정하였다. 테이핑적용 방법에 따른 전·후와 그룹 간 효과를 비교하기 위해 $\mathrm{LESS}$ 와 하지관절 각도의 변화를 평가하였다. 본 연구는 코로나19 사태로 방역지침에 따라 발열체크, 마스크 착용, 손소독제 사용, 출입자 명부 비치 등 수칙을 준수하여 진 행하였다. 연구의 설계는 Figure 1과 같다.

\section{중재 방법}

\section{무를 안정화 테이핑 기법}

본 연구에서 사용된 테이핑은 키네시오 테이핑(Kinesio 


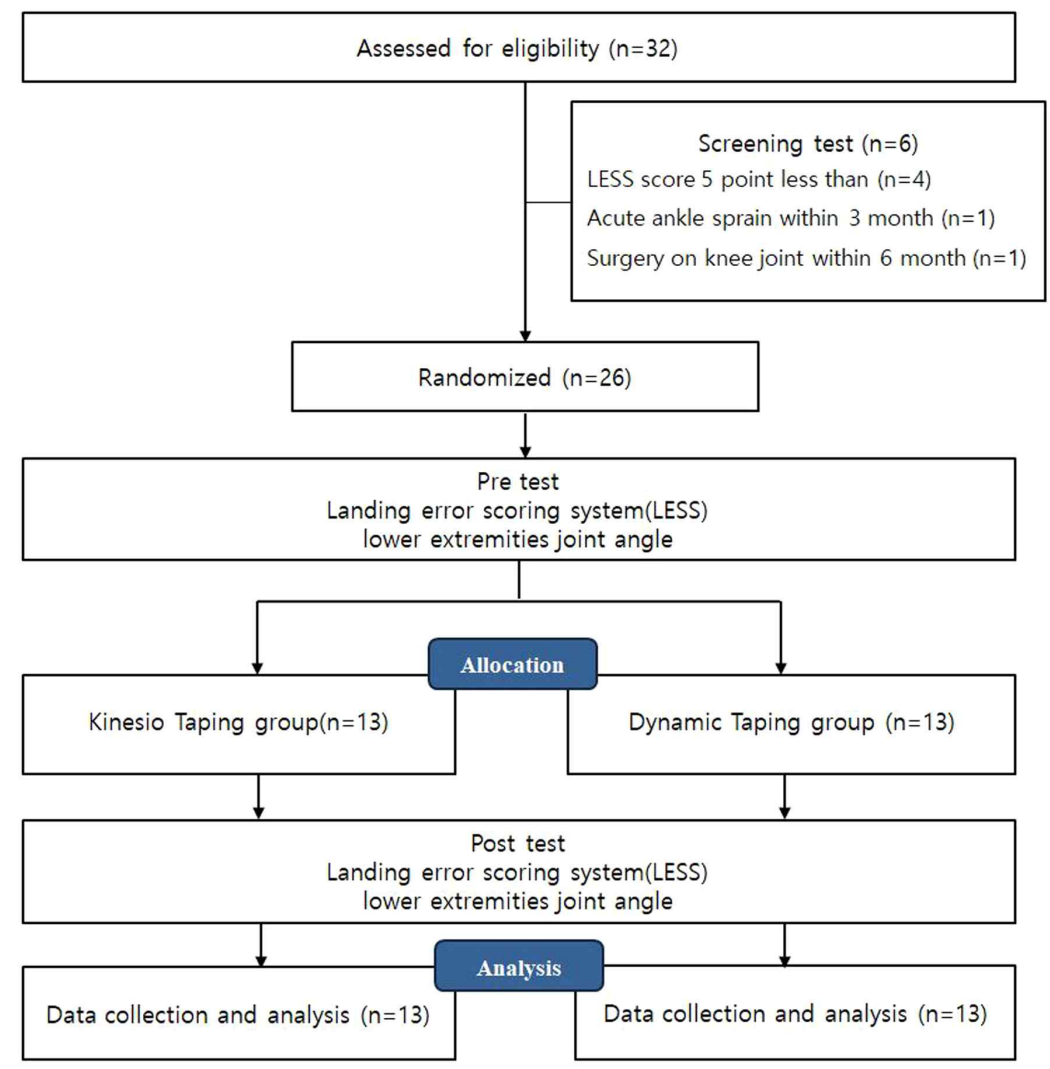

Figure 1. CONSORT flow chart

Tex Classic, Kinesio Co.)과 다이나믹 테이핑(Dynamic Tape, Port Vila, Vanuatu)으로 사용하였다. 테이핑 기법 은 KT그룹, $\mathrm{DT}$ 그룹 모두 동일한 $\mathrm{ACL}$ 테이핑 기법으로 적용 하지만 $\mathrm{KT}$ 그룹에는 테이핑 적용시 근육의 길이가 길어진 자세에서 적용하고 DT그룹은 근육의 길이가 짧아 진 자세에서 부착하였다[15,18]. 무릎 안정화 테이핑 기법
은 Kai Liu[19] 방법에 따라 테이핑을 적용하였다. 앞쪽 에는 장력은 $10 \%$ 의 테이핑 두 개를 아래앞엉덩뼈가시에 서 시작하여 넙다리 안쪽과 가쪽을 지나 정강뼈 결절에 부착하였고 뒤쪽에는 장력은 $10 \%$ 의 테이핑 두 개를 궁둥 뼈결절에서 뒤넙다리 안쪽과 가쪽을 지나 정강뼈 융기에 부착하였다(Figure 2). 마지막으로 정강뼈 결절에서 등쪽

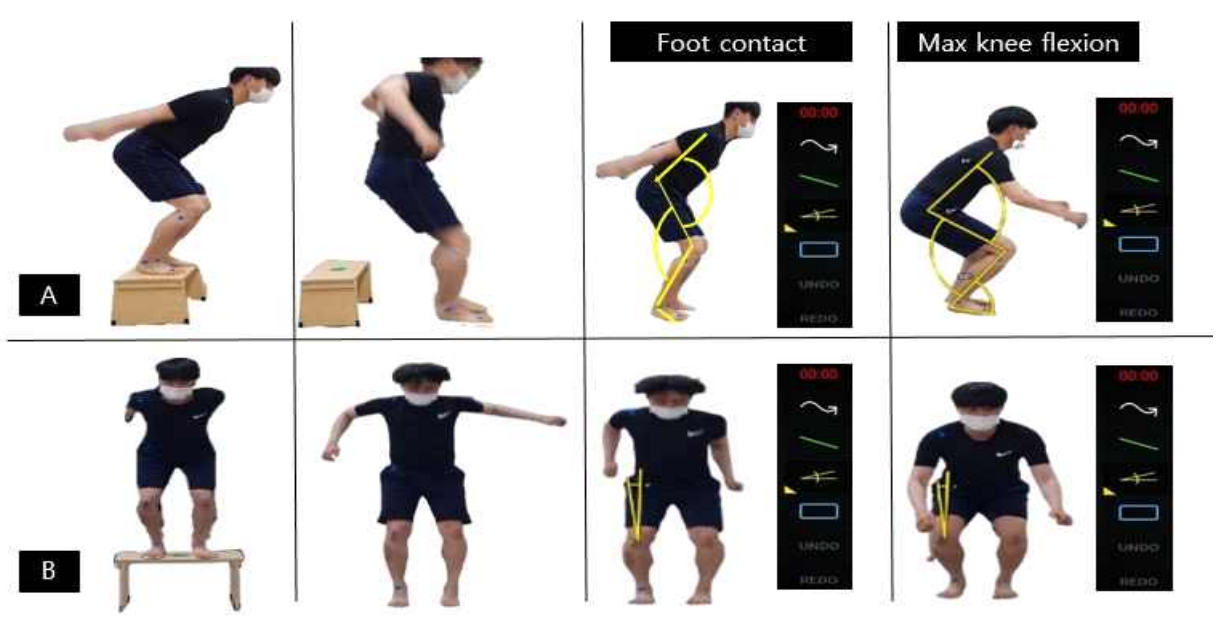

Figure 2. Using the app 'Coach's Eye', LESS and lower extremity joint angle 
으로 $20 \%$ 의 장력으로 테이핑을 부착하였다. 대상자들에 게 적용하는 모든 테이핑은 국제키네시오테이핑 레벨 (Level) 2 과정을 이수한 물리치료사 1 인이 전담하여 실 시하였다.

\section{측정방법 및 도구}

\section{착지오류 점수체계(LESS)}

$\mathrm{LESS}$ 는 착지하여 즉각적으로 도약하는 순간에 발생하 는 자세의 오류를 항목별로 점수화하여ACL 손상 위험을 평가하는 도구로 Padua[7] 방법에 따라 진행하였다. 이마 면과 시상면을 기록하는 두 대의 카메라(Galaxy S21 5G, Samsung, Korea)는 착지 위치에서 $3.5 \mathrm{~m}$ 의 거리를 두고 $1.2 \mathrm{~m}$ 높이로 설치하였고 착지를 위한 $30 \mathrm{~cm}$ 높이의 도약 대를 설치하였다. 대상자는 $30 \mathrm{~cm}$ 높이의 도약대에 서게 한 후, 본인 신장의 $50 \%$ 지점을 향해 점프 착지하여 바 닥에 닿는 즉시 가능한 한 높이 다시 뛰어오르도록 하였 다(Figure 3). 세 번의 충분한 연습 후 본 평가 3회 진행 하였다.

기록한 영상 분석은 발목관절( $\mathrm{ICC}=0.98)$, 무릎관절(ICC $=0.98)$, 엉덩관절 $(\mathrm{ICC}=0.79)$ 신뢰도를 가진 동영상 동작 분석 어플리케이션인 'Coach's Eye'(ver 6.6.0, TechSmith Corp, USA)으로 분석하였다[20]. 방법은 다음과 같다. 착 지 초기, 발 접촉, 다시 공중으로 뛰어오르기 전 무릎 관 절의 최대 굴곡 시점에서 잘못된 착지 동작을 찾아내어 점수를 기록하였다. 평가 3회에 대한 평균 값으로 이마면 영상에서는 8 가지 항목에서 최고 8점의 오류 점수를 확인 하였고 시상면 영상에서는 총 8가지 항목에서 최고 9점의 오류 점수를 확인하였다. 마지막으로 이마면과 시상면의 영상을 종합적으로 판단하여 0-2점을 부가하였다. 총 점 수는 19점 척도이며 LESS 측정결과 값이 높을수록 불안 정함을 의미한다[7]. 우수한(excellent) 착지 4점 이하, 좋 은(good) 착지 4점 이상 5점 이하, 보통(moderate) 착지

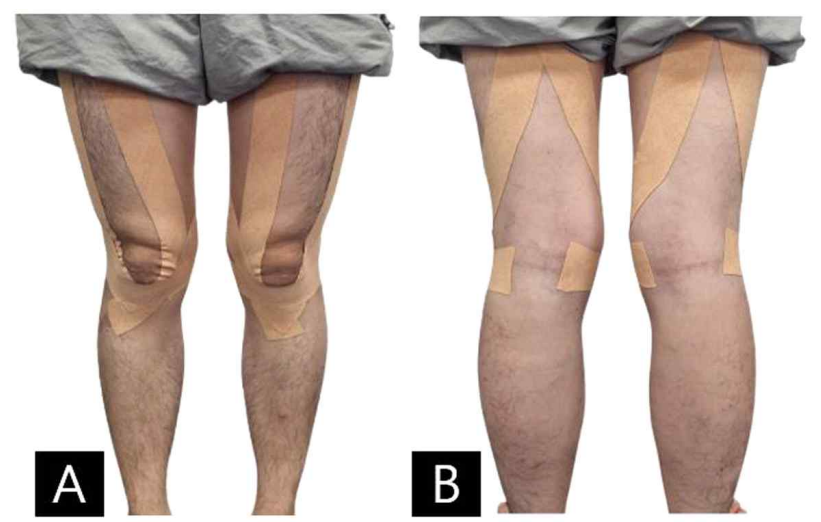

5점 이상 6점 이하, 잘못된(poor) 착지는 6점 이상으로 정의한다[7]. 본 연구는 LESS 6점 이상인 무릎 불안정성 을 가진 대상자를 선정하였다.

\section{착지시 하지 관절 각도}

착시 시 하지 관절 각도는 LESS 평가 시 기록한 영상 분석을 통해 발 접촉, 점프 전 최대 무릎 굽힘 시점에서의 관절각도를 분석하였다. 이마면에서의 무릎 외반 각도, 시 상면에서의 발목 발등 굽힘 각도와 무릎 굽힘 각도와 엉 덩 관절 굽힘 각도를 확인하였다. 무릎의 외반각도는 이 마면에서 촬영된 영상에서 무릎뼈 중심선과 위앞엉덩뼈가 시와 무릎뼈와 이은선과의 만나는 각으로 산출하였다. 발 목 발등 굽힘은 시상면에서 바깥 정강뼈 중앙에 이은선과 바깥 5 번째 발가락뼈 중앙과 만나는 선의 절대각으로 산 출하였다. 무릎 굴곡 각도는 시상면에서 넙다리뼈 바깥 중앙에 이은선과 정강뼈 바깥 중앙과 만나는 선의 절대각 으로 산출 하였다. 엉덩굽힘 각도는 시상면에서 몸통 바 깥 중앙에 이은선과 넙다리뼈 바깥 중앙에 이은선과 만나 는 선의 절대각으로 산출하였다.

\section{자료 분석}

본 연구를 통해 수집된 자료 분석은 윈도우용 SPSS 프 로그램(ver. 25.0, SPSS Inc, USA)을 사용하였다. 대상자 의 일반적 특성은 기술통계하여 평균과 표준편자 값을 제 시하였고, 카이제곱 검정(Chi-square test)과 독립표본 t검정을 통해 동질성을 확인하였다. 모든 변수의 정규성 검정을 위해 Shapiro-Wilks test를 사용하였다. 그룹 내 테이핑효과에 대한 중재 전·후 비교를 위해, 대응표본 t검정으로 분석하였으며, 그룹 간 효과를 비교하기 위해 독립표본 $\mathrm{t}$-검정으로 분석하였다. 본 연구의 통계적 유의 수준 $(\alpha)$ 은 0.05 로 설정하였다.

\section{연구 결과}

연구 대상자는 KT그룹 13 명, DT그룹 13 명 이었으며, 일반적인 특성 Table 1 에 제시하였다. 두 그룹의 일반적 특성에서 유의한 차이는 없었다.

\section{착지오류점수시스텀(LESS)}

테이핑 요법에 따른 LESS 변화는 Table 2와 같다. 전. 후 변화는 두 그룹 모두 테이핑 적용 전과 비교하여 유의 하게 감소하였다 $(\mathrm{p}<0.05)$. 그러나 그룹 간에는 유의한 차 이가 없었다.

Figure 3. Knee stability taping 
Table 1. General characteristics of subjects.

$(\mathrm{n}=26)$

\begin{tabular}{|c|c|c|c|c|}
\hline Variables & KT group $(n=13)$ & DT group $(n=13)$ & $t / x^{2}$ & $\mathbf{p}$ \\
\hline Sex (Male/Female) & $6 / 7$ & $6 / 7$ & 0.000 & 1.000 \\
\hline Age (years) & $23.84(0.65)$ & $24.00(0.72)$ & 0.157 & 0.877 \\
\hline Height (cm) & $167 \quad(2.33)$ & $169 \quad(2.37)$ & -0.530 & 0.601 \\
\hline Weight (kg) & $(3.71)$ & $(2.54)$ & 0.393 & 0.698 \\
\hline
\end{tabular}

Values are presented as mean (SD)

KT: kinesio taping, DT: dynamic taping

Table 2. Comparison in Landing error scoring system(LESS) of the kinesio taping group and dynamic taping group. ( $\mathrm{n}=26)$

\begin{tabular}{lllll}
\hline & & KT group $(\mathbf{n}=\mathbf{1 3})$ & DT group $(\mathbf{n}=\mathbf{1 3})$ & $\mathbf{t}(\mathbf{p})$ \\
\hline \multirow{2}{*}{ LESS } & Pre & $6.92(0.86)$ & $7.46(0.77)$ & $1.673(0.107)$ \\
$($ score $)$ & Post & $4.53(0.77)$ & $4.38(0.76)$ & $-.508(0.616)$ \\
& change & $2.38(0.24)$ & $3.07(0.28)$ & $1.844(0.078)$ \\
& $\mathrm{t}(\mathrm{p})$ & $9.88(0.000)$ & $10.69(0.000)$ & \\
\hline
\end{tabular}

Values are presented as mean (SD)

KT: kinesio taping, DT: dynamic taping

착지 시 하지 관절 각도

테이핑 요법에 따른 착지 시 하지 관절 각도 Table 3,
4와 같다. KT그룹 전·후 변화는 이마면 무릎 최대 굽힘 시점에서 무릎 관절 외반 각도가 유의하게 감소하였다 $(\mathrm{p}$

Table 3. Comparison in range of motion for lower extremities of the kinesio taping group and dynamic taping group at the time of foot contact.

$(n=26)$

\begin{tabular}{|c|c|c|c|c|c|c|c|}
\hline \multicolumn{2}{|l|}{ Foot contact } & \multicolumn{2}{|c|}{ KT group $(n=13)$} & \multicolumn{2}{|c|}{ DT group $(n=13)$} & \multicolumn{2}{|l|}{$t(p)$} \\
\hline \multirow{4}{*}{ hip flexion $\left({ }^{\circ}\right)$} & Pre & 53.58 & $(7.34)$ & 46.56 & (6.41) & -2.598 & $(0.016)$ \\
\hline & Post & 53.63 & $(7.55)$ & 51.86 & (9.85) & -0.513 & $(0.612)$ \\
\hline & change & -0.05 & $(1.21)$ & -5.30 & (2.38) & -1.965 & $(0.061)$ \\
\hline & $\mathrm{t}(\mathrm{p})$ & -0.042 & $(0.967)$ & -2.229 & $(0.046)$ & & \\
\hline \multirow{4}{*}{ knee flexion $\left({ }^{\circ}\right)$} & Pre & 56.66 & $(7.88)$ & 55.25 & (7.52) & -.466 & $(0.646)$ \\
\hline & Post & 57.17 & $(7.31)$ & 64.56 & $(6.33)$ & 2.752 & $(0.110)$ \\
\hline & change & -0.51 & $(1.75)$ & -9.30 & (1.97) & -3.325 & $(0.003)$ \\
\hline & $t(p)$ & -0.292 & $(0.775)$ & -4.714 & $(0.001)$ & & \\
\hline \multirow{4}{*}{ knee valgus $\left({ }^{\circ}\right)$} & Pre & 7.14 & (2.64) & 7.51 & $(4.46)$ & 0.251 & $(0.804)$ \\
\hline & Post & 6.12 & (1.84) & 5.92 & $(3.21)$ & -0.199 & $(0.844)$ \\
\hline & change & 1.02 & $(0.61)$ & 1.590 & $(0.55)$ & 0.665 & $(0.503)$ \\
\hline & $\mathrm{t}(\mathrm{p})$ & 1.660 & $(0.123)$ & 2.852 & $(0.015)$ & & \\
\hline \multirow{4}{*}{$\begin{array}{l}\text { ankle plantar } \\
\text { flexion }\left({ }^{\circ}\right)\end{array}$} & Pre & 6.94 & $(3.52)$ & 10.04 & $(4.65)$ & 1.916 & $(0.067)$ \\
\hline & Post & 6.12 & (3.32) & 9.84 & (4.18) & 2.506 & $(0.019)$ \\
\hline & change & 0.30 & $(1.40)$ & 0.20 & (1.76) & -0.046 & $(0.964)$ \\
\hline & $\mathrm{t}(\mathrm{p})$ & 0.645 & $(0.531)$ & 0.116 & $(0.910)$ & & \\
\hline
\end{tabular}

Values are presented as mean (SD)

KT: kinesio taping, DT: dynamic taping 
$<0.05)$. DT그룹 전·후 변화는 시상면발 접촉시점에서 무 릎 관절 굽힘, 엉덩 관절 굽힘 각도가 유의하게 증가하였 다 $(\mathrm{p}<0.05)$. 시상면 무릎 최대 굽힘 시점에서는 무릎 관
DT 무릎 안정화 테이핑 적용 시 점프 착지 동작에서 무릎 의 안정성을 제공한다는 것으로 설명할 수 있다. 착지 동 작 시 발생하는 지면반발력이 무릎에 큰 영향을 미치므로

Table 4. Comparison in range of motion for lower extremities of the kinesio taping group and dynamic taping group at the time of max knee flexion.

$(\mathrm{n}=26)$

\begin{tabular}{|c|c|c|c|c|c|c|c|}
\hline \multicolumn{2}{|l|}{ Max knee flexion } & \multicolumn{2}{|c|}{ KT group $(n=13)$} & \multicolumn{2}{|c|}{ DT group $(n=13)$} & \multicolumn{2}{|l|}{$t(p)$} \\
\hline \multirow{4}{*}{ Hip flexion $\left({ }^{\circ}\right)$} & Pre & 82.25 & $(12.98)$ & 75.79 & $(19.26)$ & -1.002 & $(0.326)$ \\
\hline & Post & 78.17 & $(16.67)$ & 82.38 & $(19.23)$ & 0.596 & $(0.557)$ \\
\hline & change & 4.07 & (2.89) & -6.58 & $(3.91)$ & -2.189 & $(0.039)$ \\
\hline & $\mathrm{t}(\mathrm{p})$ & 1.405 & $(0.185)$ & -1.684 & $(0.118)$ & & \\
\hline \multirow{4}{*}{ Knee flexion $\left({ }^{\circ}\right)$} & Pre & 92.92 & (12.52) & 90.12 & (15.01) & -0.515 & $(0.611)$ \\
\hline & Post & 93.04 & $(21.56)$ & 97.07 & (18.11) & 0.515 & $(0.611)$ \\
\hline & change & -0.12 & (4.19) & -6.94 & $(2.83)$ & 0.636 & $(0.191)$ \\
\hline & $\mathrm{t}(\mathrm{p})$ & -0.030 & $(0.976)$ & -2.450 & $(0.031)$ & & \\
\hline \multirow{4}{*}{ Knee valgus $\left({ }^{\circ}\right)$} & Pre & 12.25 & $(4.76)$ & 11.30 & $(4.84)$ & -0.503 & $(0.620)$ \\
\hline & Post & 10.406 & $(3.72)$ & 9.07 & $(3.48)$ & -0.942 & $(0.335)$ \\
\hline & change & 1.84 & $(0.69)$ & 2.23 & $(0.050)$ & 0.451 & $(0.656)$ \\
\hline & $\mathrm{t}(\mathrm{p})$ & 2.668 & $(0.020)$ & 4.450 & $(0.001)$ & & \\
\hline \multirow{4}{*}{$\begin{array}{l}\text { ankle dorsi } \\
\text { flexion }\left({ }^{\circ}\right)\end{array}$} & Pre & 23.66 & $(5.97)$ & 24.97 & $(4.20)$ & 0.646 & $(0.524)$ \\
\hline & Post & 21.97 & $(5.67)$ & 23.33 & $(4.84)$ & 0.657 & $(0.517)$ \\
\hline & change & 1.69 & $(1.01)$ & 1.64 & $(1.41)$ & 0.691 & $(0.997)$ \\
\hline & $\mathrm{t}(\mathrm{p})$ & 1.661 & $(0.123)$ & 1.160 & $(0.269)$ & & \\
\hline
\end{tabular}

Values are presented as mean (SD)

KT: kinesio taping, DT: dynamic taping

절 굽힘 각도가 유의하게 증가하였다 $(\mathrm{p}<0.05)$. 또한 이마 면발 접촉, 무릎 최대 굽힘 시점에서 무릎 관절 외반 각도 가 유의하게 증가하였다 $(\mathrm{p}<0.05)$

두 그룹 간에는 시상면발 접촉 시점 무릎 관절 굽힘, 무릎 최대 굽힘 시점 엉덩 관절 굽힘에서 $\mathrm{DT}$ 그룹이 $\mathrm{KT}$ 그룹보다 유의하게 더 큰 변화를 보였다 $(\mathrm{p}<0.05)$.

\section{고찰}

본 연구는 무릎 불안정성이 있는 성인에게 KT와 DT 를 적용하여 LESS 그리고 착지 시 하지 관절 운동 각도 에 미치는 영향을 알아보고자 하였다.

본 연구에서는 LESS 선별검사를 통해 6점 이하 즉 무릎 불안정성을 가진 대상자에게 테이핑을 적용하여 테이핑 적용 전·후 LESS 비교와 그룹간 LESS 비교를 하였다. 그 결과 $\mathrm{KT}$ 그룹, $\mathrm{DT}$ 그룹 전·후 변화에서 모두 유의한 감소 를 나타냈다. 그러나 그룹 간의 차이는 없었다. 이는 $\mathrm{KT}$,
안정적인 점프 착지를 수행하기 위해서는 지면반발력을 감소시키는 방법이 필요로 한다[12]. Jafarnezhadgero[21] 의 연구에서는 20 명의 남자 선수에게 $\mathrm{KT}$ 를 적용한 후 착 지 지면반발력이 $44 \%$ 감소했다고 보고하였다. 본 연구도 선행연구의 결과를 뒷받침하여 키네시오 테이핑은 무릎의 안정성을 제공하여 LESS평가에 큰 영향을 주었을 것으로 사료된다. DT 또한 키네시오 테이핑이 가지고 있는 기본 적인 특성에 더하여 $200 \%$ 이상의 더 큰 탄성력을 가지고 있어 점프 착지 시 지면반발력 감소 그리고 무릎의 안정 성을 제공하여 LESS 평가에 영향을 주었을 것으로 사료 된다.

착지 시 하지 관절 각도 그룹 간 비교에서 발 접촉 시 무릎, 최대 무릎 굽힘 시 엉덩 관절 굽힘 각도가DT그룹 에서 유의하게 더 증가하였다 $(\mathrm{p}<0.05)$. 착지 동작시 안전 한 착지 동작을 수행하기 위해서는 하지 관절 굽힘을 증 가시키는 자세가 중요하다[22,23]. 특히 안전한 각도 범위 로 착지 자세를 수행하는데 넙다리네갈래근의 근육 활동 
이 중요하다[24,25]. Lee와 Cho[26]는 스쿼트와 같이 체 중 부하 운동 중 무릎넙다리뼈 통증이 있는 16 명의 대상 자를 대상으로 무릎뼈를 고정하기 위해 강성 테이핑으로 고정하였으며 그 결과로는 안쪽넓은근의 활성도 및 근활 성도 비율이 유의하게 증가하였다 $(\mathrm{p}<0.05) . \mathrm{Ha}$ 등의 연 구에서는 DT를 이용하여 한 발 착지 시 안쪽넓은근의 활 성도가 유의하게 증가하였다는 연구결과를 보여주었다 [15]. 또한 여러 연구들에서도 무릎넙다리 통증이 있는 대 상자에게 탄력 및 비탄력 테이핑을 적용하여 보행, 계단 내려가기, 스쿼트, 점프-착지 시 무릎 동작이 즉각적으로 조절되었으며, 넙다리네갈래근의 근활성비에도 영향을 주 었다[16,27].

종합하면 임상에서 가장 흔히 사용되고 있는 탄력 테이 핑인 $\mathrm{KT}$ 는 $140 \% \sim 180 \%$ 까지의 신축성을 보이는 것과 비교해 DT는 $200 \%$ 이상의 신축성을 가지고 있어 강한 신장력과 반동력으로 KT에 비해 충격흡수, 하지 관절의 각도 변화에 큰 영향을 주었을 것이라 사료된다. 또한 적 용 기법과 관련하여 결과에 영향을 주었을 것이다. DT의 적용 방법은 KT 기법과는 반대로 근육을 수축 한 상태에 서 적용하는데, 이는 장력을 최대화 함으로써 근육-힘줄 단위가 늘어나기 시작할 때 즉시 지지를 제공한다고 말한 다[12]. 본 연구에서는 테이핑 적용시 아래앞엉덩뼈가시 에서 정강뼈 결절까지 부착한 것으로 착지 시 무릎 관절 굽힘 각도가 증가함에 따라 엉덩 관절에서도 안전한 자세 를 만들기 위해 엉덩 관절 굽힘 또한 증가한 것으로 생각 된다.

본 연구는 몇 가지 제한점을 가지고 있다. 첫째, LESS 를 통해 선별한 무릎 불안정성 대상자로 제한되어 모든 대상으로 일반화하기 어렵다. 추후 ACL손상 진단을 받은 대상으로 테이핑 비교연구가 이루어지길 기대한다. 둘째, 영상 프레임 기술로 인한 시점에 대한 영상 흔들림 현상 이 발생한다는 점이다. 본 연구는 흔들림 현상으로 각 관 절에 대한 스티커를 부착하여 각도를 확인 할 수 있었지 만, 추후 연구에는 프레임의 문제를 해결할 수 있는 기계 장치들로 진행한다면 흔들림 현상을 해결할 수 있을 것이 다. 셋째, 남성 여성 그룹을 나누지 못했다는 점이다. 남 성과 여성은 분명한 근 수행에 있어 차이가 존재한다. 이 는 결과에 성별 따른 영향이 있었을 것이라 생각된다. 추 후 특정 성별을 대상으로 연구가 이루어지길 기대한다.

\section{결론}

본 연구에서는 무릎 불안정성이 있는 성인에게 $\mathrm{KT}$ 기 법과 DT기법을 적용하여 LESS, 하지 관절 운동 각도 변 화를 알아보았다. 그 결과 두 그룹 모두 전·후 LESS에서 유의하게 감소하였고 하지 관절 각도에서는 다이나믹 테
이핑이 키네시오 테이핑과 비교하여 착지 동작 수행 시 발 접촉 시 무릎 굽힘 각도, 최대 무릎 굽힘 시 엉덩 굽힘 각도가 유의하게 감소하였다. 이는 무릎 불안정성이 있는 대상자에게 스포츠 활동과 같은 무릎 관절에 과도한 부하 와 갑작스러운 충격이 주어지는 동작 수행 시 무릎 손상 의 예방을 위해 다이나믹 테이핑을 적용한다면 무릎의 안 정성을 확보할 수 있다. 본 연구의 결과는 무릎 불안정성 있는 대상자들의 비접촉 손상의 위험을 낮추고 재활 운동 시 무릎 안정성을 위해 다이나믹 테이핑 적용을 제시하는 바이다.

\section{이해충돌}

본 연구의 저자들은 연구, 저작권, 및 출판과 관련하여 잠재적인 이해충돌이 없음을 선언합니다.

\section{참고문헌}

1. Cho YH, Choi JH, Park SW. Effect of Elastic and Non-elastic Taping on Pain, Balance, and Left / Right Step Time Difference in Patients with Acute Ankle Sprain. J Korean Soc Phys Med. 2018; 13:67-73.

2. Song JE, Choi HS, Shin WS. Effect of applying resistance in various directions on lower extremity muscle activity and balance during squat exercise. Phys Ther Rehabil Sci.2019;8:61-6.

3. Arendt $Y$, Kerschbaumer F. Injury and overuse pattern in professional ballet dancers. Z Orthop Ihre Grenzgeb. 2003;141:349-56.

4. Griffin LY, Agel J, Albohm MJ, Arendt EA, Dick RW, Garrett WE, et al. Noncontact anterior cruciate ligament injuries: risk factors and prevention strategies. J Am Acad Orthop Surg. 2000;8:141-50.

5. Harmer PA. Incidence and characteristics of time-loss injuries in competitive fencing: a prospective, 5-year study of national competitions. Clin J Sport Med. 2008;18:137-42.

6. Cowan SM, Bennell KL, Hodges PW, Crossley KM, McConnell J. Delayed onset of electromyographic activity of vastus medialis obliquus relative to vastus lateralis in subjects with patellofemoral pain syndrome. Arch Phys Med Rehabil. 2001; 82:183-9.

7. Padua DA, Marshall SW, Boling MC, Thigpen CA, Garrett Jr WE, Beutler AI. The Landing Error 
Scoring System (LESS) is a valid and reliable clinical assessment tool of jump-landing biomechanics: the JUMP-ACL study. Am J Sports Med. 2009; 37:1996-2002.

8. Kowall MG, Kolk G, Nuber GW, Cassisi JE, Stern $\mathrm{SH}$. Patellar taping in the treatment of patellofemoral pain: a prospective randomized study. Am J Sports Med. 1996;24:61-6.

9. Kang MH, Choi SH, Oh JS. Postural taping applied to the low back influences kinematics and EMG activity during patient transfer in physical therapists with chronic low back pain. J Electromyogr Kinesiol. 2013;23:787-93.

10. Williams S, Whatman C, Hume PA, Sheerin K. Kinesio taping in treatment and prevention of sports injuries. Sports Med. 2012;42:153-64.

11. Parreira PdCS, Costa LdCM, Junior LCH, Lopes $\mathrm{AD}$, Costa LOP. Current evidence does not support the use of Kinesio Taping in clinical practice: a systematic review. J Physiother. 2014;60:31-9.

12. McNeill W, Pedersen C. Dynamic tape. Is it all about controlling load?.J Bodyw Mov Ther. 2016; 20:179-88

13. Bittencourt N, Leite M, Zuin A, Pereira M, Gonçalves G, Signoretti S. Dynamic Taping and high frontal plane knee projection angle in female volleyball athletes. Br J Sports Med. 2017;51:297-8.

14. Robinson N, Spratford W, Welvaert M, Gaida J, Fearon A. Does Dynamic Tape change the walking biomechanics of women with greater trochanteric pain syndrome? A blinded randomised controlled crossover trial. Gait Posture. 2019;70:275-83.

15. Ha TW, Park SH, Lee MM. Comparison of difference in muscle activity ratio, ground reaction force and knee valgus angle during single leg squat and landing according to dynamic taping. Phys Ther Rehabil Sci.2020;9:281-6.

16. Blyth K. Kinematic outcomes following patella taping in individuals with patellofemoral pain - a crossover design [Master thesis]. Sydney: The University of New South Wales; 2019.

17. Kwon $\mathrm{OH}$, Kim H, Shin WS. Comparison of the Effects of Different Types of Taping on Static and Dynamic Balance in Adults with Chronic Ankle Instability. KSIM. 2020;8:27-36.

18. Bischoff L, Babisch C, Babisch J, Layher F, Sander
$\mathrm{K}$, Matziolis G, et al. Effects on proprioception by Kinesio taping of the knee after anterior cruciate ligament rupture. Eur J Orthop Surg Traumatol. 2018;28:1157-64.

19. Liu K, Qian J, Gao Q, Ruan B. Effects of Kinesio taping of the knee on proprioception, balance, and functional performance in patients with anterior cruciate ligament rupture: A retrospective case series. md-journal. 2019;98.

20. Krause DA, Boyd MS, Hager AN, Smoyer EC, Thompson AT, Hollman JH. Reliability and accuracy of a goniometer mobile device application for video measurement of the functional movement screen deep squat test. Int J Sports Phys Ther. $2015 ; 10: 37$.

21. Jafarnezhadgero A, Sadri A, Ghiasvand G, Majlesi M. Effects of Femoral Rotational and Abductoral Kinsio Taping on Three-Dimensional Lower Limb Kinematics during Stance Phase of Running. J Rehab Med. 2018;7(3):79-87.

22. Dufek JS, Bates BT. The evaluation and prediction of impact forces during landings. Med Sci Sports Exerc. 1990;22:370-7.

23. Devita P, Skelly WA. Effect of landing stiffness on joint kinetics and energetics in the lower extremity. Med Sci Sports Exerc. 1992;24:108-15.

24. Crossley KM, Zhang W-J, Schache AG, Bryant A, Cowan SM. Performance on the single-leg squat task indicates hip abductor muscle function. Am J Sports Med. 2011;39:866-73.

25. Kim DH, Kim KH. Immediate effects of kinesio taping on muscle fatigue of quadriceps on muscle strength and balance ability. JKPTS. 2020;27:43-50.

26. Lee SE, Cho SH. The effect of McConnell taping on vastus medialis and lateralis activity during squatting in adults with patellofemoral pain syndrome. J Exerc Rehabil. 2013;9:326.

27. Boling MC, Padua DA, Marshall SW, Guskiewicz $\mathrm{K}$, Pyne S, Beutler A. A prospective investigation of biomechanical risk factors for patellofemoral pain syndrome: the Joint Undertaking to Monitor and Prevent ACL Injury (JUMP-ACL) cohort. Am J Sports Med. 2009;37:2108-16. 